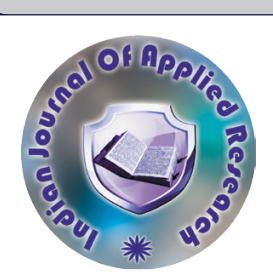

Jai Shanker Patel*

Dr. Manisha Kiran
Social Science

\title{
PSYCHOEDUCATION, IMPROVING MEDICATION ADHERENCE AMONG INDIVIDUALS WITH BIPOLAR AFFECTIVE DISORDER
} ABSTRACT AIM: aim of the present study to see the role of Psychoeducation in improvement of medication adherence among
Bipolar Disorder.

MATERIAL \& METHODS: Present study was conducted in RINAPS, Ranchi and consisted of 24 samples, comprises into two groups 12 of ( TAU) and 12 of (TAU+PE) for 2 month of having 8 sessions. After 2 month post intervention and after 4 months follow up carried out to assess the result.

RESULT AND CONCLUSION: The data analysis in the current study was done with help of non parametric test using SPSS version 20 for categorical variables chi square test, comparison between group Mann Witnney U test and for comparison within group Wilcoxon Sign Rank test was used. Post intervention finding indicates Psychoeducation is helpful in improving medication adherence among individuals with Bipolar Affective Disorder.

\section{KEYWORDS : Bipolar Affective Disorder, Psychoeducation And Medication Adherence}

\section{INTRODUCTION:}

Bipolar disorder, classically known as "manic depressive psychosis," is a serious, chronic, and relapsing mental disorder. They represent a heavy financial and social burden both direct (hospitalizations and consumption of medical resources) and indirect (constant days missed from work and loss of productivity). ${ }^{11}$ The consequences of the disorder and its subsequent relapses for the individual and for family members, combined with the high risk of mortality by suicide suggest that a multiple therapeutic effort must be made, going beyond while at the same time supportive of drug therapy ${ }^{[2]}$. Management of bipolar affective disorder is aimed at treating acute episodes, reducing the severity and frequency of future episodes and improving psychosocial functioning between episodes. Despite significant strides in the pharmacological treatment of bipolar disorder, most bipolar patients cannot be maintained on drug treatments alone. Up to $50 \%$ of bipolar patients do not recover from acute manic episode within one year and only $25 \%$ achieve full recovery of function. Rates of recurrence average $40-60 \%$ in $1-2$ years even when patient undergo pharmac otherapy. Patients spend as much as $47 \%$ of their lives in symptomatic states, especially depressive states and about $40 \%$ of patients are fully adherent with medication regimens in the year following an episode [3]. Medication can help reduce symptoms and are recommended as first line treatment for bipolar disorder. Researchers have shown that various non pharmacological therapeutic approaches like IPSRT, FFT, and CBT are effective for treatment of bipolar disorder [4]. One of these methods is Psycho education, which has been found to be helpful in reducing relapse rate, burden of illness, as well as improving symptoms and patient's functioning [5]. Psycho education is a simple therapeutic approach aimed at improves the treatment outcome of patients and enhance the prevention of future episodes. As an adjunctive treatment to standard pharmacotherapy it delivers information based behavioral training aimed at adjusting patient lifestyle and strategies of coping with disorder, including enhancement of illness awareness , treatment adherence, early detection of relapses and avoidance of potentially harmful factors such as substance misuse and sleep deprivation [6]. It is education and training about a condition that causes stress to person. Better understanding of condition leads to feeling to control and results in reduced stress associated with the condition. An education about their condition is more likely to make people actively participate in their self management and relapse prevention. This tends to brings about the individual self efficacy and the accompanying benefits from other psychotherapies and medications. Psycho education is highly effective in preventing relapse, identification of early warring sings, and treatment adherence [7].

Adherence problems, a common, feature among bipolar samples, has deserved great attention by the existing psycho educational program. Unfortunately, some patients keep on suffering relapses even when they strictly follow their prescribed somatic treatments. In addition to increasing compliance, Psycho education may focus on early recognition of symptoms of relapse, such as hyperactivity and reduced need for sleep, minimizing the risk of hospitalization through medications of the daily therapeutic regimen. Individual intervention in teaching patients to identify early symptoms of relapse has been shown to be highly effective in preventing new episodes and improving social functioning[8]

\section{METHOD \\ SAMPLE:}

After various inclusion and exclusion criterions sample were selected from the outpatient department of RINPAS, Kanke, Ranchi, Jharkhand through non probability purposive sampling technique 24 patients were selected for psychoeducation. Duration of their illness was more than one year. Both groups were matched in the socio-demographic characteristics and clinical variables. Patients were in the age range of 21 to 45 years.

\section{DESIGN:}

A pre test and post test design with control group was used in this study. Equal numbers of patients were purposively assigned to experimental and control group.

\section{TOOLS:}

\section{SOCIO-DEMOGRAPHIC \& CLINICAL DATA SHEET:-}

It is semi-structured Performa especially drafted for the purpose of present study. It contains information about Socio-Demographic variables like Name, Age, Sex, Religion, Education, Marital status, Domicile and Occupation and Clinical details like Diagnosis, Age of onset, Mode of onset, Course, Progress of illness, number of admission, number of relapse, history of severe physical illness, history of major psychiatric illness, and family history of mental illness and treatment history and Medicine Adherence Rating Scale (MARS) ${ }^{|9|}$ were used.

\section{PROCEDURE:}

Patients were selected from outpatient department as per inclusion and exclusion criterions. Sample was selected to the (TAU+PE) and (TAU) group according to sample recruitment procedure. Socio-demographic data was collected from these patients. After that medication adherence rating scale was administered to both the groups. 12 patients of group were provided psychoeducation for 8 sessions once per week for about 45-60 minutes duration. The second group was control group and left to follow routine of treatment. After the intervention both the group was administered again with medication adherence rating scale. Both groups were assessed on different outcome variable first before beginning of the therapy, second after two months and then lastly after four months of post assessment 


\section{STATISTICALANALYSIS:}

As sample size in this study was small, hence obtained date was analyzed by using non parametric statistics, namely chi square test (for categorical variables) and Mann-Whitney U Test (for continuous variables and between group comparison) Wilcoxon Signed Rank Test (for within group comparisons)

\section{RESULT}

Table 1: Comparison between Psycho education + Treatment As Usual (PE+TAU) and Treatment as Usual (TAU) on SocioDemographic Variables (Category Variables)

\begin{tabular}{|c|c|c|c|c|c|}
\hline \multirow{2}{*}{\multicolumn{2}{|c|}{ Variable }} & \multicolumn{2}{|c|}{ Group $\mathrm{N}=40$} & \multirow[t]{2}{*}{$d f$} & \multirow[t]{2}{*}{$\chi^{2}$} \\
\hline & & TAU +PE & TAU & & \\
\hline \multirow[t]{4}{*}{ Education } & Below Matric & $3(25 \%)$ & $4(33.3 \%)$ & \multirow[t]{4}{*}{3} & \multirow[t]{4}{*}{$3.27(\mathrm{NS})$} \\
\hline & Matric & $6(50 \%)$ & $3(25 \%)$ & & \\
\hline & Intermediate & $1(8.3 \%)$ & $4(33.3 \%)$ & & \\
\hline & Above & $2(16.7 \%)$ & $1(8.3 \%)$ & & \\
\hline \multirow[t]{2}{*}{ Marital status } & Single & $5(41.7 \%)$ & $7(58.3 \%)$ & \multirow[t]{2}{*}{1} & \multirow[t]{2}{*}{$0.66(\mathrm{NS})$} \\
\hline & Married & $7(58.3 \%)$ & $5(41.7 \%)$ & & \\
\hline \multirow[t]{4}{*}{ Religion } & Hindu & $11(91.7 \%)$ & $8(66.7 \%)$ & \multirow[t]{4}{*}{3} & \multirow[t]{4}{*}{$5.47(\mathrm{NS})$} \\
\hline & Islam & $0(0 \%)$ & $2(16.7 \%)$ & & \\
\hline & Christian & $0(0 \%)$ & $2(16.7 \%)$ & & \\
\hline & Others & $1(8.3 \%)$ & $0(0 \%)$ & & \\
\hline \multirow[t]{3}{*}{ Domicile } & Rural & $8(66.7 \%)$ & $11(91.7 \%)$ & \multirow[t]{3}{*}{1} & \multirow[t]{3}{*}{$2.27(\mathrm{NS})$} \\
\hline & Semi Urban & $4(33.3 \%)$ & $1(8.3 \%)$ & & \\
\hline & Urban & $0(0 \%)$ & $0(0 \%)$ & & \\
\hline \multirow[t]{4}{*}{ Occupation } & Govt. Job & $2(16.7 \%)$ & $0(0 \%)$ & \multirow[t]{4}{*}{3} & \multirow[t]{4}{*}{$6.66(\mathrm{NS})$} \\
\hline & Pvt. Job & $0(0 \%)$ & $4(33.3 \%)$ & & \\
\hline & Farmer & $4(33.3 \%)$ & $2(16.7 \%)$ & & \\
\hline & Others & $6(50 \%)$ & $6(50 \%)$ & & \\
\hline \multirow{2}{*}{$\begin{array}{l}\text { Types of } \\
\text { Family }\end{array}$} & Nuclear & $7(58.3 \%)$ & $9(75 \%)$ & \multirow[t]{2}{*}{1} & \multirow[t]{2}{*}{0.75 (NS) } \\
\hline & Joint & $5(41.7 \%)$ & $3(25 \%)$ & & \\
\hline
\end{tabular}

\section{$\mathrm{NS}=$ Not Significant}

Table 1 shows the comparison between both study groups on different socio-demographic variables. It is evident from the table that there was no significant difference between both the groups on any of the sociodemographic. Hence, both the groups were comparable and equivalent in terms of socio-demographic characteristics.

Table 2 Comparison between PE+TAU group and TAU group at baseline, post, and follow up on (MARS) Scores

\begin{tabular}{|l|l|l|l|l|l|l|}
\hline Variable & Group (Mean \pm SD) & \multicolumn{2}{|l|}{ Mean Rank } & \multirow{Z}{*}{ Z } \\
\cline { 2 - 4 } & TAU \pm PE & TAU & TAU \pm PE & TAU & & \\
\hline \multicolumn{7}{|c|}{ Baseline Assessment } \\
\hline MARS & $4.58 \pm 0.51$ & $4.41 \pm 1.08$ & 13.04 & 11.96 & 65.500 & $-0.403(\mathrm{NS})$ \\
\hline \multicolumn{7}{|c|}{ Post Assessment } \\
\hline MARS & $7.08 \pm 1.24$ & $5.41 \pm 1.08$ & 16.54 & 8.46 & 23.50 & $-2.868(.004)$ \\
\hline \multicolumn{7}{|c|}{ Follow up Assessment } \\
\hline MARS & $7.00 \pm 1.12$ & $3.58 \pm 1.44$ & 15.79 & 9.21 & 32.50 & $-2.335(.002)$ \\
\hline
\end{tabular}

Table 2 shows the comparison of the scores on the MARS between Treatment as Usual plus psychoeducation (TAU+ PE) and Treatment as Usual (TAU) Group which was done by using Mann-Whitney U test. It was found the mean value for MARS $4.58 \pm 0.51$ for psychoeducation group and $4.41 \pm 1.08$ for the (TAU) Group. There was no significant difference found between both the groups on medication adherence scores $(Z=-0.40, P>0.05)$. Table 3 shows the comparison of both groups on post assessment scores. From this part, it is clear that statistically significant difference was found between both groups in the score of medication adherence rating scale i.e. MARS $(Z=-28.68, P<.004)$.

Looking at the provided mean value, standard deviations, $\mathrm{U}$ value, $\mathrm{Z}$ value and significance level, it is evident that the participants in group psychoeducation had scored high on medication adherence rating scale. It indicates towards the significant effect of psychoeducation in improving medication adherence among individuals with bipolar affective disorder.

Another part of Table 3 shows the comparison between both the groups on follow up assessment scores on adherence scale. On this front, statistically significant difference was found between both the groups i.e. $\operatorname{MARS}(\mathrm{Z}=--23.35, \mathrm{P}<.002)$.
Follow up assessment mean value, standard deviations, $U$ value, $Z$ value and significance level indicates that even on follow up, participants in psychoeducation program scored high on medication adherence rating scale which proves that psychoeducation program was to be beneficial in improving medication adherence.

Table 3 Comparison between baseline and post scores on Medic ation Adherence Rating Scale within TAU+PE group and TAU group

\begin{tabular}{|l|c|c|c|c|c|}
\hline Variable & \multicolumn{2}{|c|}{ Group (Mean \pm SD) } & \multicolumn{2}{c|}{ Mean Rank } & \multirow{2}{*}{ Z } \\
\cline { 2 - 5 } & Baseline & Post & $\begin{array}{c}\text { Negative } \\
\text { Ranks }\end{array}$ & $\begin{array}{c}\text { Positive } \\
\text { Ranks }\end{array}$ & \\
\hline \multicolumn{7}{|c|}{ TAU+PE Group } \\
\hline MARS & $4.58 \pm 0.51$ & $7.08 \pm 1.24$ & .00 & 6.50 & $-3.07(.002)$ \\
\hline \multicolumn{7}{|c|}{ TAU Group } \\
\hline MARS & $4.41 \pm 1.08$ & $5.41 \pm 1.08$ & 4.50 & 6.15 & $-2.93(.008)$ \\
\hline
\end{tabular}

Table 3 shows comparison between baseline scores and post interv ention scores on MARS within both groups. First part of the table is showing the result of baseline assessment and post assessment scores on MARS within PE+TAU group and second part of the table is showing the same assessment within TAU group. It is evident from the table that both groups showed statistically significant improvements on post assessment in comparison to their respective baseline scores but improvement in intervention group was more significant in terms of Medication Adherence Rating Scale. Intervention group reported statistically significant differences on MARS. Similarly, TAU group also reported significant improvement on MARS as compared to baseline score. These findings indicate that psycho education along with treatment as usual brought more improvement in medication adherence compared to treatment as usual group.

Table 4: Comparison between post and follow up scores on MARS within TAU+PE group and TAU group

\begin{tabular}{|c|c|c|c|c|c|}
\hline \multirow[t]{2}{*}{ Variable } & \multicolumn{2}{|c|}{ Group (Mean \pm SD) } & \multicolumn{2}{|c|}{ Mean Rank } & \multirow[t]{2}{*}{$\mathrm{Z}$} \\
\hline & Post & Follow up & $\begin{array}{c}\text { Negative } \\
\text { Ranks }\end{array}$ & $\begin{array}{c}\text { Positive } \\
\text { Ranks }\end{array}$ & \\
\hline \multicolumn{6}{|c|}{ TAU+PE Group } \\
\hline MARS & $7.08 \pm 1.24$ & $7.00 \pm 1.12$ & 6.00 & 5.00 & $-0.265(\mathrm{NS})$ \\
\hline \multicolumn{6}{|c|}{ TAU Group } \\
\hline MARS & $5.41 \pm 1.08$ & $3.58 \pm 1.49$ & 14.50 & 21.50 & $-0.513(\mathrm{NS})$ \\
\hline
\end{tabular}

Table 4 shows the comparison between post intervention scores and follow up intervention scores on MARS within both the groups. First part of the table is showing the result of post assessment and follow up assessment scores on MARS within PE+TAU group and second part of the table is showing the same assessment within TAU group. Results of this table indicate that the intervention group and control group did not show further improvement in MARS total $(p>0.05)$ which means though they did not improve further on follow up but maintained the gains which were previously acquired during post intervention phase.

\section{DISCUSSION:}

The present study aimed to examine the effect of psychoeducation in improving medication adherence among individuals with bipolar affective disorder. In this study table 1 show all patients were male, age range 21-45 years. Most of them belong to different place of rural backgrounds, educated up matric and belong to nuclear family and work as daily wage worker. Table 1 reveals that equally both group matched married and unmarried domains of marital status respectively. Majority of patients belong to Hindu religion. In medication adherence related studied similar age groups were widely used, because of persons from similar age group are more vulnerable to poor medication adherence so in this way majority of the participants were from same age group George et al. (2013) ${ }^{[10 \mid}$ In contrast, earlier studies by Klinkenberg et al, ${ }^{[11]}$ Carpenter et al, ${ }^{[12]}$ and Nose et al, ${ }^{[13]}$ have observed a relatively higher non-adherence in young population. Present finding showed that psycho educative interventions as an adjunct pharmacotherapy of bipolar disorder produce significant improvement in medication adherence $(\mathrm{p}<0.004)$. These findings are similar to the study findings of Pakpour A. H., Modabernia, A., Lin, C.$\mathrm{Y}$, et al. (2017) ${ }^{[14 \mid}$ by showing improved medication adherence more in patients of experimental group (baseline score $=6.03$, score at six month $=9.55$ ) than in patient of controlled group (baseline score $=6.17$, score at six month=6.567). Another study did by Javadpour et al. (2013) ${ }^{\mid 15}$ also found a considerable improvement in quality of life, medication adherence as well as frequency of hospitalization in 18 
months follow up intervention based on psychoeducation. Mc. Donald et al. $(2016)^{[16]}$ a Meta analysis of 18 studies showed improvement in adherence to medication in intervention group compared to control group. Similarly systematic review of randomized controlled trials of psychoeducation in participants with bipolar disorder compared with treatment as usual and placebo or active interventions group of Bond K., \& Anderson I. M., (2015) $)^{[17]}$ proved that psychoeducation improved medication adherence and short term knowledge about medication. Vieta $(2005)^{[181}$ reported that, as an adjunct to pharmacotherapy, psychoeducation is a promising management component the increases treatment adherence and quality of life for patients. Treatment as usual group also had an increased adherence which may be due to the monitoring done by therapist in terms of intake of medicines.

\section{LIMITATIONS:}

This study held a small group of participants with few sessions and short follow up period and its sample was male only. Another limitation of the study is multiple indicators were not used to assess the adherence to medication and there was no control over the medication regimen prescribed by the consultant.

\section{CONCLUSION:}

Present study may have implications for the dissemination of effective psychoeducation in routine treatment of persons with bipolar affective disorder. Continuous follow up, support of family members, key relatives and health care team members can improve the adherence to treatment. Psychoeducation program should be provided for ambulatory and hospital patients and psychoeducation for families should be made a part of routine practice.

\section{REFERENCES:}

1. Colom F, Vieta E. Psychoeducation manual for bipolar disorder. 1st ed. Cambridge: Cambridge University Publication. 2006; 3

2. Yadav J, Sharma SK, Singh L, Singh T, Chauhan D. bipolar disorder in adults. International Research Journal of Pharmacy. $20134(6): 34-8$

3. Miklowitz DJ. Adjunctive psychotherapy for bipolar disorder: state of the evidence. Miklowitz DJ. Adjunctive psychotherapy for bipolar
American Journal of Psychiatry. 2008 165(11):1408-19.

4. www.nimh.nih.gov/health/topics/bipolardisorder/index.shtml

5. Bordbar MR, Faridhosseini F. Psychoeducation for Bipolar Mood Disorder. In Clinical, Research and Treatment Approaches to Affective Disorders 2012. In Tech.

6. Stafford N, Colom F. Purpose and effectiveness of psychoeducation in patients with bipolar disorder in a bipolar clinic setting. Acta Psychiatrica Scandinavica. 2013; 127 (Suppl. 442):11-8.

7. Yadav S, Kar SK. Model of Psychoeducation: Indian Perspective. Indian Journal of Applied Research. 2014 4(7): 422-23

8. Colom F, Vieta E, Reinares M, Aran AM, Torent C,, Goikolea JM et al. Psychoeducation efficacy in bipolar disorders: beyond compliance enhancement. J Clin Psychiatry. 2003; 64(9):1101-5.

9. Thompson K, Kulkarni J, Sergejew A. Reliability and validity of a new Medication Adherence Rating Scale (MARS) for the psychoses. Schizophr Res 2000; 42 (3): 241-7. doi: 10.1016/S0920-9964(99)00130-9

10. George, L. S., Sharma, P. S. V. N., \& Nair, S. (2013). Effect of psycho-educative intervention on adherence to treatment, knowledge and attitude among persons with bipolar affective disorder (BPAD)-randomized controlled trial. J Nurs Health Sci, 1, 12-7.

11. Klinkenberg, W. D., \& Calsyn, R. J. (1996). Predictors of receipt of aftercare and recidivism among persons with severe mental illness: a review. Psychiatric Services.

12. Carpenter, P. J., Morrow, G. R., del Gaudio, A. C., \& Ritzler, B. A. (1981). Who keeps the first outpatient appointment?. The American journal of psychiatry.

13. Nosé, M., Barbui, C., Gray, R., \& Tansella, M. (2003). Clinical interventions for treatment non-adherence in psychosis: meta-analysis. The British Journal of Psychiatry, 183(3), 197-206.

14. Pakpour, A. H., Modabbernia, A., Lin, C. Y., Saffari, M., Asl, M. A., \& Webb, T. L. (2017). Promoting medication adherence among patients with bipolar disorder: a multicenter randomized controlled trial of a multifaceted intervention. Psychological medicine, 47(14), 2528-2539.

15. Javadpour, A., Hedayati, A., Dehbozorgi, G. R., \& Azizi, A. (2013). The impact of a Javadpour, A., Hedayati, A., Dehbozorgi, G. R., \& Azizi, A. (2013). The impact of a
simple individual psycho-education program on quality of life, rate of relapse and medication adherence in bipolar disorder patients. Asian journal of psychiatry, 6(3), 208-213.

16. MacDonald, L., Chapman, S., Syrett, M., Bowskill, R., \& Horne, R. (2016). Improving medication adherence in bipolar disorder: A systematic review and meta-analysis of 30 years of intervention trials. Journal of affective disorders, 194, 202-221.

17. Bond, K., \& Anderson, I. M. (2015). Psychoeducation for relapse prevention in bipolar disorder: a systematic review of efficacy in randomized controlled trials. Bipolar disorders, 17(4), 349-362.

18. Vieta, E. (2005). Improving treatment adherence in bipolar disorder through psychoeducation. The Journal of clinical psychiatry, 66, 24-29. 